\title{
Care for Patients with Complex Needs: Canadian Results from the Commonwealth Fund 2015 International Health Policy Survey of Primary Care Physicians
}

Christina Lawand, Geoff Paltser, Grace Cheung and Alison Ytsma

\begin{abstract}
Good primary care is essential for the effective management of patients with chronic conditions in the community and to ensure their care is well coordinated with other parts of the system. The Commonwealth Fund 2015 International Health Policy Survey compares the views and experiences of primary care physicians in $\mathbf{1 1}$ countries including Canada. The survey found nearly all $(98 \%)$ primary care doctors across countries treat patients with complex needs in their practice. However, when examining questions on chronic disease management and coordination of care with other providers, Canadian results are mixed compared to the international average, and show variation at the provincial level. Opportunities likely exist to learn from other countries that have a more systematic approach to primary care delivery.
\end{abstract}

\section{Introduction}

For most people, primary care physicians are the first point of contact with the healthcare system. They provide and coordinate care to manage health problems in the community and help to prevent people from getting sick in the first place. Research shows that effective primary care provides better overall care for patients at a lower cost to the health system. Across Canada, there have been many efforts to improve the delivery of primary care (Beaulieu et al. 2013; Government of Canada 2012).

By providing comparable information on the experiences of primary care physicians in 11 countries, the Commonwealth Fund 2015 International Health Policy Survey of Primary Care Physicians provides an important perspective on how well primary care works in Canada and where improvements still need to be made (Canadian Institute for Health Information 2016; Commonwealth Fund 2015).
Of the many topics covered in the survey, primary care physicians were asked questions about managing complex patients with chronic diseases and coordination of care for these patients across the healthcare system. These questions are highly relevant given that more than $65 \%$ of Canadian seniors have multiple chronic conditions such as heart disease, cancer, asthma, diabetes, arthritis and dementia (Public Health Agency of Canada 2010). These individuals are often high users of the health system and face significant challenges to their quality of life. However, many chronic conditions (referred to as ambulatory care sensitive conditions) can be managed in the community through appropriate delivery of primary care, thereby avoiding or delaying costly hospitalizations and further deterioration of health.

\section{Methodology}

The Commonwealth Fund 2015 International Health Policy Survey of Primary Care Physicians polled primary care physicians in 11 countries: Australia, Canada, France, Germany, the Netherlands, New Zealand, Norway, Sweden, Switzerland, the United Kingdom and the United States. Data from France were not available at the time this analysis was conducted. In Canada, there were 2,284 respondents and an overall response rate of $31.7 \%$.

The survey data for Canada were first weighted within each of the 10 provinces by age and gender. Data were, subsequently, weighted by province to reflect Canada's primary care physician distribution. Owing to small sample sizes, detailed provincial and territorial results are not shown for Prince Edward Island, Nunavut, Northwest Territories and Yukon.

Statistical testing was performed to determine whether Canadian and provincial results were significantly different from the international average of 10 countries. 


\section{Results}

The Commonwealth Fund 2015 International Health Policy Survey of Primary Care Physicians found that $98 \%$ of Canadian doctors see patients with multiple chronic conditions. This is on par with the average of all countries surveyed (Figure 1). A similar proportion (96\%) of doctors said that their practice is well or somewhat prepared for these patients, slightly below the international average (98\%).

\section{FIGURE 1.}

Proportion of primary care physicians whose practice often/sometimes sees patients with multiple chronic conditions

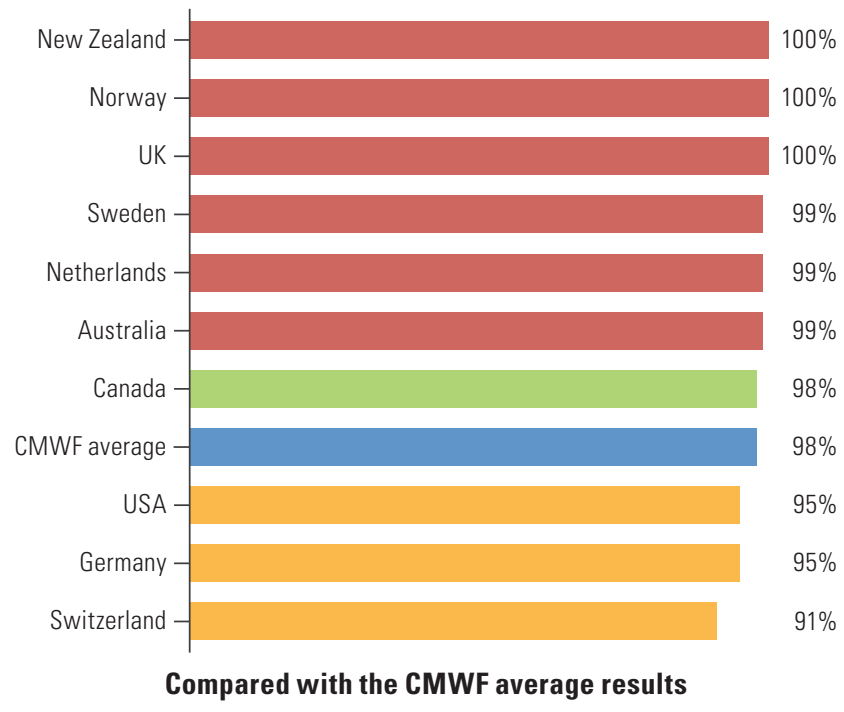

CMWF average Above average Same as average Below average

Primary care physicians can manage their patient's chronic conditions in a variety of ways. Canadian primary care physicians were asked if their practice uses personnel, such as nurses or case managers, to monitor and manage care for patients with chronic conditions and if their practice gives written instructions about how their patients with chronic conditions can manage their own care at home. Responses varied across provinces, yet results were largely below the international average (Table 1 ).

Patients with chronic conditions often require specialist care. Canadian primary care physicians are more likely to receive information, such as changes made to medications or care plans, from their patient's specialists than doctors in other countries (Table 2). However, there is room for improvement overall in coordination of care with specialists. As well, Canada ranked below the international average for coordination with other sectors such as home care and social services.
TABLE 1.

Management of patients with chronic conditions, by province

\begin{tabular}{|c|c|c|}
\hline & $\begin{array}{l}\text { Proportion of physicians } \\
\text { whose practice uses } \\
\text { personnel, such as nurses or } \\
\text { case managers, to monitor and } \\
\text { manage care for patients with } \\
\text { chronic conditions that need } \\
\text { regular follow-up care (within } \\
\text { and outside of practice) }\end{array}$ & $\begin{array}{l}\text { Proportion of physicians } \\
\text { whose patients with } \\
\text { chronic conditions are } \\
\text { routinely/occasionally } \\
\text { given written instructions } \\
\text { about how to manage their } \\
\text { own care at home }\end{array}$ \\
\hline $\mathrm{BC}$ & $53.7 \% *$ & $83.3 \% \S$ \\
\hline$A B$ & $80.2 \%{ }^{\Uparrow}$ & $81.3 \% \S$ \\
\hline SK & $68.5 \% \S$ & $79.8 \% *$ \\
\hline MB & $53.0 \% *$ & $80.3 \% \S$ \\
\hline ON & $57.2 \%{ }^{*}$ & $73.7 \% *$ \\
\hline $\mathrm{OC}$ & $73.2 \%{ }^{\S}$ & $73.9 \% *$ \\
\hline NB & $64.2 \% *$ & $79.9 \%$ * \\
\hline NS & $59.4 \% *$ & $87.2 \% \S$ \\
\hline $\mathrm{NL}$ & $53.4 \% *$ & $78.3 \% *$ \\
\hline Canada & $63.7 \%{ }^{*}$ & $77.2 \%^{*}$ \\
\hline $\begin{array}{l}\text { CMWF } \\
\text { average }\end{array}$ & $72.7 \%$ & $87.2 \%$ \\
\hline \multicolumn{3}{|c|}{ *Below CMWF average. ${ }^{\text {sS }}$ Same as CMWF average. 'Above CMWF average. } \\
\hline \multicolumn{3}{|c|}{$\begin{array}{l}\text { TABLE } 2 \text {. } \\
\text { Extent of coordination between primary care physicians }\end{array}$} \\
\hline
\end{tabular}

When their patient has been seen by a specialist, Canadian primary care physicians always received

A report back from the specialist with all relevant health information

Information about changes the specialist made to the patient's medication or care plan

Information that is timely and available when needed $13 \%$ * $\quad \mathbf{9 \%}$

${ }^{*}$ Above CMWF average

\section{Discussion and Conclusion}

Individuals with chronic conditions, particularly those with multiple chronic conditions, are frequent users of the healthcare system. The Commonwealth Fund 2015 International Health Policy Survey of Primary Care Physicians shows that almost all Canadian doctors see these patients in their practice.

Proper management of patients with chronic conditions in primary care can help to improve outcomes and increase efficiency. However, most Canadian provinces perform 
significantly below the international average with respect to utilizing case managers or other health professionals to manage care for patients with chronic conditions and providing these patients with written instructions on how to manage their care at home. These are only two measures of chronic condition management, and suggest that Canada can learn from other countries that may have a more systematic approach to primary care delivery of services to complex patients and perform above average in these measures.

Coordination of care between different parts of the health and social services system is also critically important for patients with complex needs, yet results for Canada are mixed. Canada performs slightly above the international average when it comes to coordination between primary care physicians and specialists. However, results are low overall for coordination with specialists and show room for improvement. Canada also performs below the international average in measures of primary care coordination with home care and social services, which is important for those with complex needs - though there is significant provincial variation in these measures. HQ

\section{Acknowledgements}

Core funding for The Commonwealth Fund 2015 International Health Policy Survey of Primary Care Physicians was provided by The Commonwealth Fund with co-funding from the following organizations outside of Canada: Bureau of Health Information (Australia); La Haute Autorité de Santé (France); the Caisse Nationale d'Assurance Maladie des Travailleurs Salariés (France); BQS Institute for Quality and Patient Safety (Germany); the German Federal Ministry of Health; the Dutch Ministry of Health, Welfare and Sport; the Scientific Institute for Quality of Healthcare, Radboud University Nijmegen (The Netherlands); the Norwegian Knowledge Centre for the Health Services; the Swedish Ministry of Health and Social Affairs; the Swiss Federal Office of Public Health; the Health Foundation (United Kingdom); and other country partners.

The Canadian Institute for Health Information (CIHI) and the Canadian Institutes for Health Research (CIHR) are national co-partners on the Commonwealth Fund Survey data.
Funding for an expanded Canadian sample was provided by Canada Health Infoway, the Commissaire à la santé et au bienêtre du Québec and Health Quality Ontario. Additional information that highlights the Canadian story can be found online at <https://www.cihi.ca/en/commonwealth-survey-2015>. Full data sets of the survey results are available to researchers upon request atcmwf@cihi.ca.

\section{References}

Beaulieu, M.D., J. Haggerty, P. Tousignant, J. Barnsley, W. Hogg, R. Geneau et al. 2013. "Characteristics of Primary Care Practices Associated with High Quality of Care.” CMAJ 185(12): E590-6.

Canadian Institute for Health Information (CIHI). 2016. How Canada Compares: Results from The Commonwealth Fund 2015 International Health Policy Survey of Primary Care Physicians. Ottawa, ON: Author. Retrieved February 29, 2016.

The Commonwealth Fund. 2015. 2015 Commonwealth Fund International Survey of Primary Care Physicians in 10 Nations. New York, NY: The Commonwealth Fund. Retrieved February 29, 2016.

Government of Canada. 2012. About Primary Health Care. Ottawa, ON: Author. Retrieved February 29, 2016.

Public Health Agency of Canada. 2010. The Chief Public Health Officer's Report on the State of Public Health in Canada 2010. Ottawa, ON: Author. Retrieved February 29, 2016.

\section{About the Authors}

Christina Lawand is a senior researcher with the Health System Analysis and Emerging Issues Department at $\mathrm{CIHI}$. Christina leads the development of analytical projects that help identify and address the health priorities of Canadians.

Geoff Paltser, PhD, is a senior analyst in Health Reports at $\mathrm{CIHI}$ in Toronto, Ontario. He is responsible for performing analyses, providing methodological support to projects and writing reports.

Grace Cheung, MSc, is a senior analyst in Health System Research at $\mathrm{ClHI}$ in Toronto, Ontario. She is responsible for performing analyses, providing methodological support to projects and writing reports.

Alison Ytsma is a senior analyst in Health System Research at $\mathrm{ClHI}$ in Toronto, Ontario. She is responsible for performing analyses, providing methodological support to projects and writing reports.

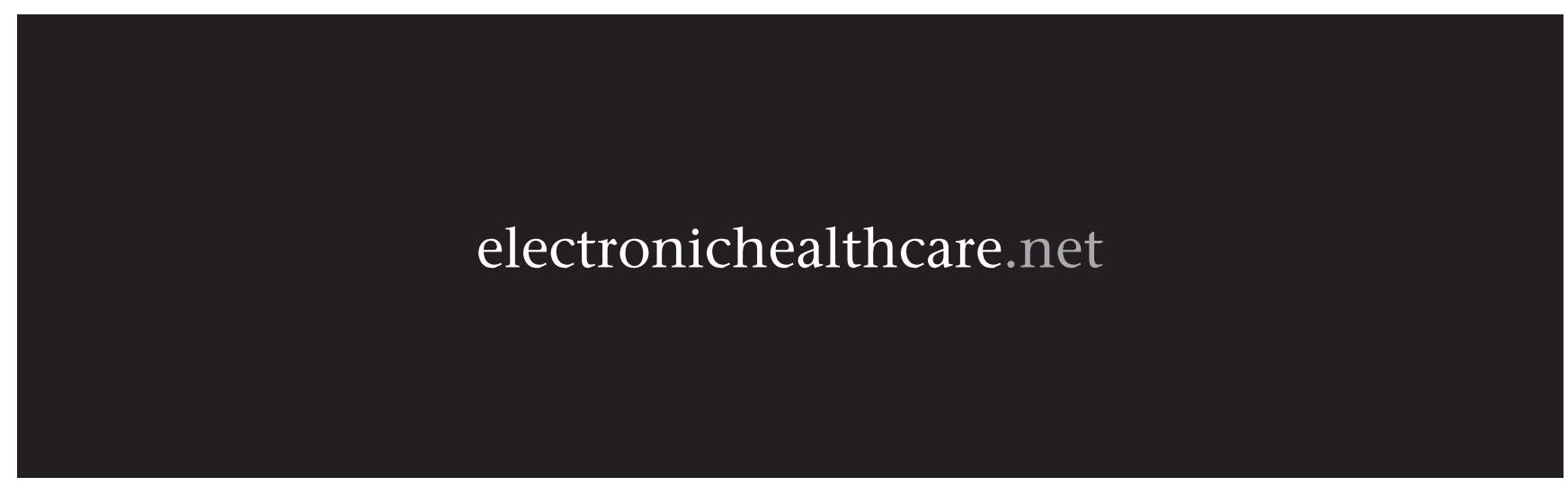

